Original Research Paper

\title{
Entrenching Inferences in Implicational and Illocutionary Constructions
}

\author{
Francisco José Ruiz de Mendoza Ibáñez \\ Department of Modern Philologies, University of La Rioja, Logroño, Spain \\ Center for Research in the Applications of Language, University of La Rioja, Logroño, Spain
}

\section{Article history}

Received: 07-05-2015

Revised: 29-05-2015

Accepted: 01-06-2015

Corresponding Author:

Francisco José Ruiz de Mendoza

Ibáñez

Department of Modern

Philologies, University of La

Rioja, Logroño, Spain

Email: francisco.ruizdemendoza@unirioja.es
Abstract: The starting point for the present paper is the classification of constructions, understood as fixed pairings of form and meaning, into four levels of meaning representation, i.e., the argument-structure, implicational, illocutionary and discourse levels. The meaning part of constructions contains fixed and variable elements. In argument-structure constructions the fixed elements are generic and, as such, they are open to parameterization through the integration of lower-level lexical structure into them. For example, the 'caused-motion' construction, which takes the form $\mathrm{X}$ CAUSES Y TO MOVE Z, can parameterize 'cause to move' by means of such predicates as 'push', 'kick' and 'drag'. In constructions from other levels of description, the fixed part, which is non-generic, contains sets of conditions that are stably realized by specific formal configurations, which are highly idiomatic. For example, the sentence Who's been messing up the bulletin board? is usually not a question about the identity of the person that has performed the described action, but an expression of irritation on the part of the speaker at someone having handled the notices on the board inefficiently. The underlying configuration, which can be labeled Who's Been VP-ing (Y)?, is an implicational construction whose VP componentwhich completes the past perfect form of the fixed part-is necessarily a progressive form, thus indicating that the action has taken place in the recent past and is of consequence to the present moment. The rest of the meaning cannot be derived compositionally but is obtained from previous inferential activity based on the non-grammatical content of the "VP Y" part of the construction: People are expected not to misuse what is not theirs. Such content is a matter of socio-cultural conventions that regulate human interaction with other humans and the inferences originally derived from it have become entrenched through frequent association with the expressive pattern that now constitutes the formal part of the construction. The same is the case with illocutionary meaning, which is often captured by idiomatic constructions. For example, Can't you please stop making noise? derives its combination of directive and expressive force (it is a request and a complaint at the same time) from the entrenchment of meaning implications arising from the fact that it is not socially acceptable for people to act in ways that bother other people. Along these lines, the paper explores other such socio-cultural conventions, examines the type of inferences that they underlie and makes correlations with formal expression patterns. Such a correlation reveals networks of meaning relations among formal patterns that enable us to give structure to the implicational and illocutionary segments of the 'constructicon' of English. It also sets up explicit connections between the constructional and inferential domains of linguistic research.

Keywords: Construction, Meaning Implication, Illocution, Socio-Cultural Convention, Lexical-Constructional Model 


\section{Introduction}

The starting point for the present paper is the classification of constructions, understood as fixed pairings of form and meaning (Goldberg, 1995; 2006), into four levels of meaning construction. These are the argument-structure, implicational, illocutionary and discourse levels. This classification, which is part of the architecture of the Lexical Constructional Model (LCM; Ruiz de Mendoza and Mairal, 2008; Mairal and Ruiz de Mendoza, 2009; Ruiz de Mendoza, 2013; Ruiz de Mendoza and Galera, 2014), is based on the distinction between high-level and low-level situational and non-situational cognitive models. As we will see below, implicational and illocutionary constructions are both based on situational cognitive models, while argument-structure and discourse constructions exploit non-situational cognitive models. What is more, implicational and illocutionary constructions capture meaning that arises from the same kind of cognitive activity. The only difference between them is a matter of the degree of genericity of the situational cognitive models underlying them.

The meaning part of constructions contains fixed and variable elements. In argument-structure constructions the fixed elements are generic and, as such, they are open to parameterization through the integration of lower-level lexical structure into them. For example, the caused-motion construction, which takes the form X CAUSES Y TO MOVE Z (Goldberg, 1995), can parameterize 'cause to move' by means of such predicates as 'push', 'kick' and 'drag': Two thugs pushed him into the back room, The child kicked the ball into our tent, They dragged the man out of his car. The verbal predicate expresses manner of motion, while the construction supplies the causal ingredient and both the construction and the verb convey a change of location. Other well-known cases of argument-structure constructions are the following: ditransitive (He gave Mary a book), dative (He gave a book to Mary), resultative (The dog licked the bowl clean), instrument-subject (The crane lifted the beam) and middle (The water filtered well). The literature on constructions of this kind in English is immense. Levin (1993) provides an initial systematic, although basically descriptive, listing of alternating constructions. Other studies focus on one construction type, such as Colleman and De Clerck (2008) on ditransitives with envy and forgive, or on a whole family of constructions as is the case of the studies on resultatives made by Boas (2003) and by Goldberg and Jackendoff (2004). There are a growing number of studies of constructions in other languages. Two examples are Barðdal et al. (2014) on the dative subject construction in several dead languages (Old NorseIcelandic, Latin, Ancient Greek, Old Russian and Old
Lithuanian) and the study carried out by Nolan (2013) on ditransitives in Modern Irish. Argument-structure constructions are abstractions over lower-level predicate-argument configurations, in particular those captured by verbal predicates. For example, it is not difficult to see the origin of the resultative construction in predicates containing a resultative ingredient, such as break '(cause to) become broken', freeze '(cause to) become frozen', or kill 'cause to become dead'. In English, when the verbal predicate cannot provide the specific type of result that the speaker wants to communicate, it is possible to use a secondary predication making such a result explicit. For example, hammering an object can bring about a whole range of possible results (e.g., the object can become broken or change its shape in many different ways). Such results can be expressed in English by means of adjectival phrases (e.g., The blacksmith hammered the iron flat) or prepositional phrases (e.g., The blacksmith hammered the iron into knives).

In constructions from other levels of description, the fixed part, which is non-generic, contains sets of conditions that are stably realized by specific formal configurations, which are fixed and idiomatic. A straightforward example is the What's $X$ Doing $Y$ ? (e.g., What's Mary doing living in Madrid?), first studied by Kay and Fillmore (1999). In this construction, the non-variable elements act as prompts for the addressee to construct a situation that is not necessarily progressive (e.g., What's she doing believing everything that quack has told her?), which depicts a state of affairs that bothers the speaker. This meaning does not arise compositionally from a descriptive reading of the combination of the constituent parts of the sentence, but is attached to it on the basis of its frequent use in situations where whatever is the case is thought by the speaker to be evident to both speaker and hearer. Thus, despite its interrogative form, this construction is not used to ask a question. We will return to this construction below. A different, but somehow related constructional configuration, which we will discuss in detail later, is illustrated by the sentence Who's been messing up the bulletin board?, which has received no special attention in the literature. This sentence could be, but is usually not, a question about the identity of the person that has performed the described action. Instead it is more easily understood as an expression of irritation on the part of the speaker at someone having handled the notices on the board inefficiently. In the LCM, the underlying configuration, labeled Who's Been VP-ing (Y)?, like What's X Doing Y?, is considered an implicational construction. In Who's Been VP-ing (Y)?, the VP component completing the past perfect form of the fixed part is necessarily a progressive form, thus indicating that the action has taken place in the recent past and is of consequence to 
the present moment. The rest of the meaning cannot be derived compositionally but is obtained from previous inferential activity based on the nongrammatical content of the "VP Y" part of the construction: People are expected not to misuse what is not theirs. Such content is a matter of socio-cultural conventions that regulate human interaction with other humans and the inferences originally derived from it have become entrenched through frequent association with the expressive pattern that now constitutes the formal part of the construction. The same is the case with illocutionary meaning, which is often captured by idiomatic constructions. For example, Can't you please stop making noise? derives its combination of directive and expressive force (it is a request and a complaint at the same time) from the entrenchment of meaning implications arising from the fact that it is not socially acceptable for people to act in ways that bother other people. A similar but more programmatic view of illocutionary constructions can be found in Stefanowitsch (2003), who argues that so-called indirect speech acts are in fact constructions that lose the meaning of the direct speech act (e.g., a question about ability in the Can/Can't You X? configurations).

Along the preceding lines, the present paper explores a number of socio-cultural conventions, examines the type of inferences that they underlie and makes correlations with formal expression patterns. Such correlations reveal networks of meaning relations among formal patterns that enable us to give structure to the implicational and illocutionary segments of the 'constructicon' (or set of all constructions) of English. They also set up explicit connections between the constructional and inferential domains of linguistic research.

\section{Construction Types}

In Cognitive Linguistics, constructions are generally described as entrenched form-meaning (or function) pairings of varying sizes and degrees of complexity (Goldberg, 1995; 1998; 2003; 2006). Since, following Goldberg, any form-meaning pairing, at whatever level of complexity, has constructional status, it follows that constructions range from the smallest meaning-making linguistic units (i.e., morphemes), through lexical items, phrases, predicate-argument configurations and conventionalized indicators of personal (e.g., modals) and interpersonal meaning (e.g., coded illocutions), to the highest linguistic units (i.e., conventionalized discourse configurations). There are three perspectives from which we can classify constructions. The first perspective looks at constructions in terms of how they combine with other constructions on the grounds of pure compatibility, i.e., without one structure getting adapted to the other. This kind of combination has been termed amalgamation (Ruiz de Mendoza, 2013). The second perspective has to do with the possibility of specifying all (or a relevant part of) the meaning elements of a construction by incorporating into them lower-level structure. This conceptual integration process has been termed subsumption (Ruiz de Mendoza and Mairal, 2008). The third perspective relates to the kind of knowledge structure or structures that support constructional meaning. We briefly examine these three perspectives in the following subsections, although only the second and third perspectives will be of interest for the central topic of the present paper, i.e., implicational and illocutionary constructions.

\section{Self-Standing Vs. Non-Self-Standing Constructions}

As evidenced in detailed work by Boas (2003), any sense of a lexical item is a construction, since it pairs form and meaning. The same holds for idiomatic expressions (e.g., kick the bucket 'die'). Lexical items and idiomatic expressions are self-standing, i.e., they do not need to be combined with other linguistic units to make sense. However, lexical items can be combined, i.e., amalgamated, into compounds of various kinds, e.g., arrowhead $(\mathrm{N}+\mathrm{N})$ 'the pointed tip of an arrow', hearsay $(\mathrm{V}+\mathrm{V})$ 'rumor', overdose $(\operatorname{Prep}+\mathrm{N})$ 'excessive dose', undervalue $(\mathrm{Prep}+\mathrm{V})$ 'value at a low price'. One interesting feature of such amalgams is that their meaning is often non-compositional, in the sense that the meaning of the whole is not necessarily a function of the meaning of the parts. For example, hearsay refers to unverified information that people hear and pass on to others by word of mouth (sometimes not in exactly the same terms). The idea that the information thus conveyed is unsubstantiated, which goes beyond the default interpretations of hear ('perceive sounds') and say ('express in words'), can be traced to real-life scenarios where people unduly disclose (usually private or confidential) information as soon as they get it. Scenarios like this act as a licensing factor for the amalgam of 'hear' and 'say' to be possible with the meaning that it has conventionalized.

An affix, whether inflectional or derivational, is also a construction, since it carries meaning associated with its grammatical function. For example, English plural $-s$ indicates that there is a multiplicity of entities, past tense -ed situates an action or an event in the past, the prefix un involves negation (unhappy) and -ness is used to indicate that a property can be conceived as an abstract entity (happiness). Unlike lexical items and idiomatic expressions, affixes are dependent on other constructional items (typically, lexical items, whether single or in amalgams), which means that they are not self-standing. However, they contribute generic-level meaning to the lexical structure to which they apply. We discuss this issue in some more detail later on. We now move on to the second and third perspectives, which will be the focus of attention here. 


\section{Parameterizable Vs. Non-Parameterizable Constructions}

Regular syntactic patterns associated with a genericlevel range of meanings are also constructional. A stock example is the sentence Pat sneezed the foam off the cappuccino (cf. Goldberg, 1995). This sentence makes use of sneeze in a causal-transitive sense that we do not normally assign to this inherently intransitive (and noncausal) verb (e.g., Who sneezed?), which can only take a complement that is governed by the preposition at (e.g., That amount of money is not to be sneezed at). There are other verbs that can be transitivized in a similar way, as evidenced by the use of laugh, snort and snore in the following sentences: She laughed her coffee out of her nose, They laughed him out of the room, He snorted blood out of his nostrils, He could snore the paint off the ceiling of his bedroom. The underlying meaning pattern is the same for all these examples, to wit, there is a forceful action such that it causes an object to move from one location to another. This meaning pattern, which is based on generic-level concepts such as 'action', 'motion' and '(change of) location', exceeds verbal meaning. Constructionists argue that this extra nonlexical meaning, to which verbal meaning becomes adapted, arises from the caused-motion construction (Goldberg, 1995; 2006). The adaptation is generally referred to as coercion, following Pustejovsky (1993) and Michaelis $(2003 ; 2004)$ and it requires the conceptual and syntactic structure of the verb to become subservient to constructional requirements of the same kind. In the case of sneeze the verb is required to take a non-oblique complement and a causal sense. We will briefly return to this issue in another section. What is important to note now is the fact that the generic-level elements of the caused-motion construction are to be specified through the integration into the construction of conceptually compatible low-level structure, which is found in association with lexical items. Verbs like sneeze, laugh, snort and snore are examples of such lexical items, since they invoke actions that can set other objects in motion thus causing a change of location. The process whereby a lexical item fleshes out (part or all of) the generic-level structure of a construction can be termed parameterization (Ruiz de Mendoza, 2013).

There are constructions that make use of fixed (i.e., non-parameterizable) and variable elements rather than just syntactic patterns associated with generic-level meaning patterns. This is the case of the caused-motion construction. A clear example is What's X Doing Y?, mentioned above. This construction conveys the meaning that the speaker is bothered by the action that he is asking about. This meaning is not directly derivable from the question itself, which is literally a question about what a certain acting entity is doing. Rather, it is obtained on the basis of pragmatic implication (now stably associated with the form What's X Doing Y?) stemming from the use of this kind of question in contexts where it is evident that the speaker does know the answer to his question. This draws the hearer's attention away from the content of the question to the speaker's attitude about the content and, on a subsequent level of interpretation, to whether some action is being required. What constructions like What's X Doing Y? actually do is use partially fixed versions of syntactic patterns that would normally give rise to argumentstructure constructions and add extra meaning implications. Illocutionary constructions work in the same way. Think of Can You (Please) X?, used to make requests, as in Can you (please) uncork the bottle? The argument-structure value of this sentence is that of a polar interrogative, i.e., asking whether the hearer has the ability to perform an action or not. But this value can be overridden through pragmatic reasoning. In contexts where it is evident that the speaker would like the action to be performed, a question about the hearer's ability to perform an action (one of Searle's well-known preparatory conditions for the speech act of requesting; Searle (1969)) redirects the hearer's attention to the social convention whereby we are expected to help other people (even without being asked) if we notice that they need it. The question about ability exploits the following line of reasoning: "You haven't done action A (e.g., uncork the bottle); since it is evident that I would like A to be done, I must assume that perhaps you do not have the capacity to do A, so let me ask."

Construction Types and Knowledge Structure:
High/Low-Level and Situational/Non-Situational
Cognitive Models

Underlying grammatical function there is high-level conceptual activation grounded in our sensorimotor experience of the world, i.e., in our experience with objects, their properties, their relations and how we can put them into different perspectives. Much of the cognitive-linguistic literature following Langacker $(1987 ; 2000 ; 2008)$ and Talmy $(2000 a ; 2000 b)$ has been devoted to exploring how language is shaped by knowledge organization and construal phenomena (Dirven and Ruiz de Mendoza (2010), for an overview). For example, the inflectional mark of "plural" in English is evidently related to the notion of 'multiplicity', which is based on our experience of counting objects of the same kind that can be perceptually dissociated from one another. Although the notion of "multiplicity" is abstract, its origin is perceptual. For this reason, Lakoff (1987) treats it as "images-schematic" in his discussion of image schema transformations. As is well known, an image schema is an embodied pre-conceptual pattern based on our sensorimotor experience (Johnson, 1987; Hampe, 2005; Peña, 2003; 2008). Such notions as 'in' 
vs. 'out', 'front' vs. 'back', 'up' vs. 'down' and other more complex notions like 'motion forward/backward along a path' and 'part-whole structure' relations are image-schematic. Image-schematic thinking shows in language in different ways. For example, we use image schemas to talk about abstract experience: I got into/out of trouble makes metaphorical use of the notion of motion into and out of a 'container' (or a bounded region in space) to express a change of state; part of the logic of this metaphor is based on the fact that the conditions inside a container can only affect the entities that get into it. In turn, an image schema transformation, as discussed by Lakoff $(1987 ; 1989)$, is a natural relationship between two image schemas that gives rise to polysemy. The sentence Fans poured through the gate illustrates what Lakoff (1987) calls the multiplex-mass image schema transformation. The plural noun fans literally denotes a collection of individuals of the same kind, but in this sentence these individuals are treated as if they were a mass. This is possible because of a perceptual phenomenon. As we move farther away, a group of people at a certain point begins to look like a mass. Evidently, the multiplex-mass transformation is a high-level metaphor licensed by perceptual experience (Peña and Ruiz de Mendoza, 2009).

Another case of grammatical function that is strongly linked to high-level conceptualization is argumentstructure relations. Three basic relations between verbs and arguments, which underlie three different kinds of predication, are monotransitivity, transitivity and ditransitivity. Canonically, these basic relations correspond to events where one, two, or three entities are involved in a predication, as in The wind is blowing, $\mathrm{He}$ took an aspirin and He gave her a ring. However, there are ways to re-construe events that can be paralleled through specific constructional re-arrangements. Inchoatives (The door opened), middles (My car handles well) and passives (The door was opened, The car was handled) have received very detailed attention in this respect (Hundt, 2007). These three constructions have been developed with a view to playing down the importance of the causer in a caused event. In the three constructions the semantic object becomes a syntactic subject. But this happens in different ways. In passives the object becomes the matized (i.e., a given element) and the agent is schematized to such an extent that it becomes syntactically optional. This results in a highly focalized verbal process. In inchoatives and middles the semantic object becomes the syntactic subject and the agent is completely dropped out of the constructions: *The door opened by the wind (Radden and Dirven, 2007). It has been argued that this rearrangement has the effect of presenting a caused event as if it were a noncausal process, which is in fact a metaphorical reconstrual of the real structure of the event. The same holds for middles, which generally differ from inchoatives in the presence of an obligatory evaluative element: *My car handles; see Ruiz de Mendoza and Peña (2008) and Ruiz de Mendoza and Mairal (2011) for details on this view. Although possible causal agents are usually retrievable from world knowledge or the context of situation both for inchoatives and middles, one of the meaning implications of these constructions is that the causal agent is irrelevant. This is not the case with passives, which do allow for the agent to be expressed in the form of an optional satellite (The door was opened by the wind).

Linguistic descriptions within the area of transitivity make use of such notions as 'agent', 'patient', 'object', 'instrument', etc. These notions, which label semantic and syntactic roles, are elements of an 'action' high-level cognitive model, i.e., they are abstractions over the components of the event-denoting lower-level cognitive models invoked by such verbal predicates as kill, break, heat, etc. The area of transitivity goes beyond the agentpatient/object relationship. Actions on objects can have results. The English resultative and caused-motion constructions are used to express result, for example. Resultant states can take the form of newly acquired properties. This is the case of the resultative construction (as in the extension of the transitive The blacksmith hammered the metal into The blacksmith hammered the metal flat). Alternatively, they can involve a change of location. This may bring with it an associated change of environmental conditions for the object (e.g., The child kicked the ball into the net).

As noted in the previous section, the caused-motion construction is an argument-structure configuration. This is so because its structure has been created by abstracting away formal and functional properties of verbal predicates involving contact by impact causing motion, as is the case of the verbs hit, kick and push. Other predicates that do not share these properties can be used with the caused-motion construction only if there is a licensing factor. Some such factors have been discussed in Ruiz de Mendoza and Mairal (2008) and Ruiz de Mendoza (2013), which deal with a broad range of cases of lexical-constructional integration. One of them, which has been labeled Predicate-Argument Conditioning in Ruiz de Mendoza (2013), is a matter of mere co-instantiation consistency between a predicate and all of its arguments. The verb sneeze, for example, can be seen as causing the motion of a light object, like the foam topping one's coffee, but not of a heavy object. Because of this, a sentence like \#She sneezed the car off the driveway is odd and requires special interpretation strategies (e.g., in the context of humor). Another licensing factor is re-construal, which may take the form of an event-structure metaphor (Lakoff, 1993), i.e., a metaphor where an event type is interpreted in terms of another event type with which it shares some high-level meaning implications. For example, the use of laugh in They laughed him out of the room is possible only if 
we reinterpret the target-oriented laughing activity leading to self-instigated motion $a s$ if it were a situation where a person is caused to leave a room through a forceful action (cf. They kicked him out of the room). Event-structure metaphors have been relabeled high-level metaphors in (Ruiz de Mendoza and Mairal, 2008; Ruiz de Mendoza and Baicchi, 2007) because they involve non-situational generic conceptual structure (such notions as agent, object, activity, action), which is definitional of the meaning pole of argument-structure characterizations.

Discourse constructions also use high-level, nonsituational cognitive models, but these are nonparameterizable fixed elements that set up different connections between such models: Logical (e.g., causeeffect, evidence-conclusion), temporal (e.g., precedence, simultaneity) and conceptual (similarity, contrast, conditioning, concession). These connections are not necessarily exclusive of one another, but can converge thereby giving rise to multiple discourse perspectives. For example, in The bomb went off and three people died, which illustrates the use of the $X$ And $Y$ construction, the precedence relationship (the bomb exploded first and then the three people died) conflates with the cause-effect relation between the explosion and the people dying. The fixed element in this example is highly schematic: and instructs hearers to relate, on the basis of their world knowledge, two predications each depicting an event. Other discourse constructions impose greater constraints on the variable elements. This is the case of concessive constructions. Consider Although $X$, Y: Although no one was killed in the blast, the device caused massive damage. Here, the event depicted in the $\mathrm{X}$ part, which is taken as true, is posed as contrasting with what is depicted in the Y part.

Implicational constructions and illocutionary constructions are based on situational cognitive models. The difference between these two construction types is simply a question of the degree of genericity of their underlying situational cognitive models. Let us start with implicational constructions. Think of everyday situations with common elements that we store in our minds, such as going to the dentist, teaching a class, taking a taxi, doing the housework, buying groceries, going on a shopping spree, etc. These scenarios have usually been termed scripts, especially in the field of Artificial Intelligence following seminal work by Schank and Abelson (1977). Scripts are internally coherent knowledge structures consisting of sequences of events within a given context or stereotyped sequences of actions that define a well-known situation (Ruiz de Mendoza, 2014a). They can be classified in a number of different ways. For example, Schank and Abelson (1977) distinguished situational, instrumental and personal scripts. The first consist of a number of participants with interlocking roles within an identified situation (e.g., 'eating in a restaurant'). The second type prescribes sequences of actions in a rigid order, with only one participant (e.g., 'starting an engine'). The third type is based on sequences of actions directed to someone's own goals. In another classification, which has been proposed in Ruiz de Mendoza (2014a), scripts are divided up into simple, complex and composite. Briefly, a simple script consists of a sequence of constitutive actions. For example, 'reading a book' requires taking the book, opening it, reading in it, turning its pages and closing the book. Other actions are not constitutive (e.g., finding a place with enough light, putting the book back on a shelf, etc.). A complex script is a chained sequence of single scripts, which thus work as subscripts, as is the case of 'going to the airport to take a flight', which includes buying the tickets, taking transportation to get to the airport, checking in, dropping the luggage, boarding the plane, flying to one's destination, getting off the plane and reclaiming the luggage. Finally, a composite script is made up of a main script and any number of independent (i.e., self-standing) subscripts, none of which is indispensable for the main script. By way of illustration, consider 'doing the housework', which may contain 'washing the dishes', 'doing the laundry', 'cleaning the carpets', 'making the beds', etc. However, what is important about them is that, whatever their degree of complexity and the way in which the entities in them relate, they are an important source of inferences in everyday life. For example, imagine that the speaker sees his neighbor next door struggling to open her door while holding a rather unmanageable big paper bag against her chest. Imagine further that the speaker's neighbor rarely buys too many groceries at the same time, so he finds this situation to be uncommon. In this context, if the speaker says to his neighbor That's a rather bulky bag, isn't it?, there are several possible interpretations. In one of them, he may be expressing his astonishment at the size of the bag and wondering why his neighbor has chosen to buy so many groceries this time. His utterance may be taken to mean ' $I$ find it strange that you have bought so many groceries; this is not typical of you; could you tell me why you have?' This interpretation is, to a large extent, the result of inferences based on the combination of a personal script about his neighbor's buying behavior mingled with partial structure from a stereotyped (situational) script about how people do their shopping, which includes alternative subscripts on how their shopping is delivered (e.g., they may carry various types of bags or they may use the delivery service provided by the store). The shopping script is an example of a complex script, but the sentence in the "bulky bag" example -in the interpretation that we have given to it here- only makes 
use of partial script structure (in fact coming from a single script within a sequence) related to one specific way of taking home the items purchased. But this interpretation is also the result of constructional behavior. The configuration That's a Rather $X(Y)$, where $\mathrm{X}$ is an NP containing an evaluative adjective (i.e., within the sequence of $\mathrm{Adj} .+\mathrm{N}$ ) and $\mathrm{Y}$ is optional, is used to express that there is something challenging or otherwise undesirable -from the speaker's point of viewabout the state of affairs associated with what is being described: That's a rather large sum (e.g., the sum is such that one can hardly afford paying it); That's a rather simplistic idea (one that the speaker thinks inadequately oversimplifies a problem); That's a rather personal question (a question that should have not been asked out of respect for one's privacy); That's a rather tender subject (the subject can easily hurt people); That's a rather unusual costume for a president (an outfit that a president should not wear). Adjectives with positive connotations do not work well with this construction (cf. \#That's a rather good person; \#That's a rather great idea; \#That's a rather nice personal question), which has the ability to add negative, evaluative overtones to adjectives whose default value is neutral. In one of the examples above, That's a rather large sum, the adjective large takes on a negative value that is not one of its regular features (cf. He had a large role in the negotiations; He inherited a large amount of money; The painting fills up a large wall). In addition, this construction presupposes that the state of affairs it designates is the case or that someone has evident intentions to make it hold.

It must be noted that the construction That's a Rather $X(Y)$ requires scripted knowledge specific to $\mathrm{X}$ and, whenever it is the case, to $Y$. These scripts are low-level situational cognitive models such as paying an amount of money, oversimplifying a complex situation, intruding someone's privacy through inappropriate questions, hurting someone by bringing up a sensitive issue, etc. Once a low-level situational model has been activated to profile a meaning interpretation that is compliant with the basic constructional value of That's a Rather $X(Y)$, as sketched out above, the resulting meaning representation can serve as the input for the activation of further, higher-level knowledge structures and their associated constructions. Thus, in the context that we provided above, the sentence That's a rather bulky bag, isn't it? can give rise to various illocutionary values associated with cultural conventions on negative states of affairs. A very common illocutionary interpretation would be that the speaker is going to offer help to hold the bag while his neighbor opens the door, thereby functioning as a pre-offer, i.e., a preparatory act for the offer to be made (e.g., That's a rather bulky bag, isn't it? Let me help you). Other interpretations are possible: The speaker may be drawing the hearer's attention to the foolishness of carrying too much weight in a single paper bag (the sentence would thus work as a mild reproach, a warning, or even a piece of advice). How is this possible? The answer is to be found in socio-cultural conventions, which themselves are situational cognitive models, like scripts. However, these conventions are more generic than scripts, since they range over many possible low-level situations. The details of this approach to illocution can be found in Ruiz de Mendoza and Baicchi (2007), Baicchi and Ruiz de Mendoza (2010) and also in Ruiz de Mendoza and Galera (2014). This approach develops previous work found in Ruiz de Mendoza (1999; 2001) and in Pérez and Ruiz de Mendoza, (2002). Ruiz de Mendoza and Baicchi (2007) have formulated a complex cognitive model, called the Cost-Benefit Cognitive Model, which is partly an extension of the well-known pragmatic scale of the same name postulated by Leech (1983). The Cost-Benefit Cognitive Model contains a number of stipulations, which underlie some politeness conventions, but which in fact go well beyond the domain of politeness into the broader domain of socio-culturally regulated interpersonal behavior. In the case of the illocutionary interpretation of our example as a pre-offer, the underlying convention is:

If it is manifest to $\mathrm{A}$ that a particular state of affairs is not beneficial to B and if A has the capacity to change that state of affairs, then A should do so.

The pre-offer matches the first condition in the stipulation above: The speaker reveals to his neighbor that he is aware that she has trouble to open the door because of the size of the bag that she is carrying. The context of situation supplies information that satisfies the second condition, i.e., the assumption that the speaker has the ability to hold the bag for her while she opens the door. The actual offer (Let me help you) matches the "then" part of the stipulation, since the offer presupposes that the speaker is willing to change the negative state of affairs in a way that will benefit the hearer.

It must be noted that the stipulation cited above also underlies other forms of verbal behavior with their own illocutionary import. For example, for the context outlined above, we can have other ways of offering: I see you're carrying a very bulky bag. Can I help you?; Shall I hold your bag while you open the door?. It's rather bulky; What a bulky bag. Do you need help? With a slight change in the context, we could have directive expressions. Imagine that the speaker is with his son, who is young and strong. There is an additional (and complementary) cultural expectation that the person that has greater capacity to help others will self-select to do so before other 
people try. This would license remarks like the following: That's a rather bulky bag. Johnny will help you; Johnny, can't you see Mrs. Jones needs help?; Johnny, help Mrs. Jones, can't you see she's having trouble?; You should help Mrs. Jones; etc. These formulations are instantiations of fixed pairings of form and illocutionary meaning, i.e., they are illocutionary constructions: Let Me X, Can I Help You?, Shall I X?, Do You Need X? are generally used to make offers; $X$ Will Help You, if $X$ refers to the speaker, is an offer (or a promise in some contexts), but if $X$ refers to a third person it is either an expression of reassuring belief or, more commonly, a request to such a person to help the hearer; Can't You See $X$ (Needs Y)? (where Y saturates easily with expressions like help, a hand, sleep, medical attention, since these are common objects of need) also has directive value tinged with a degree of reproach. Literally, with expressions like this one, speakers show their perplexity at the hearer's not helping someone in need; asking about the possibility that the hearer may not be aware of the negative situation is a way of finding a socio-culturally acceptable justification-in terms of the first condition of the stipulation noted above-for their inaction; Help $X$, which is strongly directive, can be mitigated by a complementary Can't You See X? construction suggesting possible hearer's unawareness.

As the discussion above has made clear, implicational and illocutionary constructions are selfstanding parameterizable constructions with fixed and (constrained) variable elements, which respectively exploit low-level and high-level situational cognitive models. Low-level situational cognitive models are, in terms of Cognitive Linguistics, the equivalent of what Schank and Abelson (1977) labeled scripts within the context of the initial Artificial Intelligence approaches to knowledge structure. In the following section, we shall discuss in more detail the kind of meaning that is captured in implicational and illocutionary constructions. We will do so from the point of view of how low-level situational cognitive models are actually exploited to make inferences that can become entrenched through repeated use within a community of speakers.

\section{Implicational Constructions}

We argued that That's a Rather $X(Y)$ is an implicational construction, which conveys the idea that the speaker feels that the state of affairs described by the expression is undesirable, although only from his perspective. The tag isn't it?, which looks for verification, is fully consistent with this meaning implication (note the slight oddity of saying That's a rather bulky bag, I'm sure of it). There are other implicational constructions that also convey the idea that there is something negative about a given state of affairs. The next subsections will deal with two other cases: What's X Doing $Y$ ? and Who's Been V-ing X?.

\section{What's $X$ Doing $Y$ ?}

The What's X Doing Y? construction (e.g., What's your sister doing working for the state?) has been briefly touched upon above. Its full analysis is complex, as evidenced by its detailed treatment in Kay and Fillmore (1999). For our purposes, it is enough to mention a few of its characteristics: Formally, i.e., from a morphosyntactic perspective, this construction needs the verb do in gerund (cf. *What's your sister working for the state? and note the difference in meaning of What did/will you sister do working for the state?); doing has no progressive aspect (cf. What's your sister doing knowing the answer?, *She is knowing the answer); the construction cannot take the modifier else (*What else is your sister doing working for the state?); the main verb is be (*What does your sister keep doing working for the state?); doing cannot take the negative form (*What's your sister not doing working for the state?), but its complement can (What's your sister doing not going to work today?).

We may wonder what motivates these peculiarities and how they relate to the highly schematic subjective meaning that the construction conveys. But before we go into this issue, we need to understand better some aspects of the construction that have not been discussed in Kay and Fillmore (1999). Here we will elaborate on some observations made in Ruiz de Mendoza and Mairal (2008). We shall start by comparing these other examples of the same construction:

(1)

a. What's your sister doing?

b. What's your sister doing in the lab?

c. What's your sister doing in the lab at midnight?

d. What's your sister doing in the lab at midnight with her boyfriend?

The examples in (1) require a slightly different treatment from the examples where doing is followed by a less generic verbal form in gerund (e.g., What's your sister doing working in the lab?). This is so because the less generic verbal form, which is part of the Y element of the construction, acts as a specification of the kind of activity in which the protagonist (i.e., the hearer's sister) is involved, whereas in the examples in (1) the Y element is either left unrealized or, if realized, it supplies situational details that can allow the hearer to work out the kind of activity that the speaker has in mind. This is easily noticeable from a comparison of (1a) with (1b)(1d). The question in (1a) is not a clear realization of What's $X$ Doing $Y$ ?, since the Y element, which is not 
optional in the construction, is missing. In a default interpretation, (1a) is a question about what the hearer's sister is doing. Only in a context in which whatever the hearer's sister is doing is evident to both the speaker and the hearer can (1a) be treated as an example of the What's $X$ Doing Y? construction. In this situation, the Y variable is realized inferentially and developed as much as is needed for satisfactory understanding. Examples (1b)-(1d) develop the Y element to different degrees. This has consequences for the adjustment of the generic meaning of doing: (1b) and (1c) suggest that the hearer's sister is working; however, (1d) carries the strong meaning implication that the hearer's sister is misusing the laboratory for some kind of love-related activity. In essence, the $\mathrm{Y}$ element either defines a context for the meaning of doing to be inferentially specified, which is the case of the examples in (1), or supplies the meaning through a less generic verbal form, as in What's your sister doing working in the lab? A couple of words of caution are in order at this stage. First, as was noted in a previous section, implicational constructions have fixed and variable elements. The fixed elements cannot be parameterized; the variable elements cannot either. The variable elements can be realized through conceptually compatible elements, as exemplified by (1b)-(1d) above, or even developed inferentially on the basis of equally compatible contextual information. Second, it may happen, as discussed with reference to doing in the examples in (1), that a fixed element requires adjustment. This is not a case of parameterization, which we studied as a matter of incorporating lowerlevel conceptual structure into a grammatically (rather than lexically) marked high-level characterization. Rather, it is a case of linguistically or contextually cued pragmatic adjustment of a lexically expressed highlevel concept. For example, the causative variant of the resultative construction (e.g., The blacksmith hammered the metal flat) has an underlying causal element that is activated by the combination of a transitive structure and a secondary predication that is ascribed to the object of the action. This causal element can be parameterized by a number of compatible verbal predicates such as hammer, pound and beat. By contrast, doing in What's your sister doing (working) in the lab? does not incorporate any lower-level structure. It is specified in the same way as in other uses of generic do. A case in point is the use of do in do the dishes 'wash', do the carpets 'clean', do one's hair 'style, arrange', do one's face 'apply cosmetics to', etc. These adjustments have been accounted for in Ruiz de Mendoza and Pérez (2001) as applications of the high-level metonymy GENERIC FOR SPECIFIC, i.e., a generic item affords access to a specific item that is consistent with the rest of the relevant information provided by the linguistic expression or the context. For example, in the sentence You do the dishes while I do the floors and John does the rest of the house, the highly generic characterization do ("perform the action that is typically associated in this context with the dishes/floors/rest of the house') needs specification in much the same way as doing needs specification in the What's $X$ Doing $Y$ ? construction.

Let us now take What's your sister doing working in this lab? There is a difference between this question and the questions in (1) other than the way to specify the item doing. While the constructional meaning in any of the examples in (1) could be overridden in specific contexts, this is not a clear possibility when the specification of doing is carried out on the basis of a following gerund (in this case, working). This endows this latter form of instantiation of the $\mathrm{Y}$ variable of the construction with a greater degree of formal specialization and thereby with lesser potential ambiguity.

However, there is another way of endowing the formal part of the construction with a high degree of specialization. As initially noted in Ruiz de Mendoza (2001), the greater the amount of elaboration of the instantiating elements for the $\mathrm{Y}$ variable of the construction, the more difficult it is to cancel out the implication that something is wrong from the speaker's point of view (Ruiz de Mendoza, 2001; Ruiz de Mendoza and Mairal, 2008). Compare the following developments of the examples in (1):

(1')

a. What's your sister doing? Is she still working in her lab? b. What's your sister doing in the lab? Is she still working?

c. What's your sister doing in the lab at midnight? Is she still working?

d. What's your sister doing in the lab at midnight with her boyfriend? Is she still working?

The default interpretation of the first interrogative of the examples in (1') can be taken as an instantiation of the What's $X$ Doing Y? construction or as a case of a $\mathrm{Wh}$ information question. Although (1'a) and (1'b) can be either, the preference is to think of them as information questions. The situation with (1'c) and (1'd) is not exactly the same. In the case of ( 1 'c) there is a stronger implication that the speaker feels that the situation is at least unusual. This implication can be attributed to the fact that the scenario invoked by the components of the Y variable is "negatively loaded". Thus, working at midnight is generally not a desirable scenario (although it may be a necessary one, for example, in a situation in which it may not be a good idea to cease working on an experiment until it is completely finished or if there is a strict deadline ahead to publish 
the results). But we can also derive a similar meaning implication from other more neutral scenarios: What's your sister doing in the lab now?; What's your sister doing in the lab with the new robot?; What's your sister doing in the lab at this stage? Then, the case of ( 1 'd) is worth special comment in relation to its $\mathrm{Y}$ variable. The situation depicted in this example departs in two ways from what one would expect to be acceptable behavior: one, by being at midnight in the lab; the other by being with someone that is not supposed to be there. Of course, the hearer's sister boyfriend could be a co-worker, but the fact that the speaker chooses to mention him in his role as a "boyfriend" is pragmatically significant. In this context of implications, the second question may count as a case of irony. Of course, if the speaker believes that the hearer's sister is not working, asking whether she is working becomes an echo of what she should be doing, but this is at the same time in sheer contrast with what it is suggested to be the case (The notion of "echo" has been applied by relevance theorists to explain irony; see especially Wilson (2006), Wilson and Sperber (2012) and the cognitive-linguistic development of this notion in Ruiz de Mendoza and Galera (2014) and Ruiz de Mendoza (2014b)).

So far, our discussion has allowed us to examine the importance of the Y variable in the What's X Doing Y? formal configuration in order to actually determine whether or not we are faced with a genuine example of the What's $X$ Doing Y? construction, i.e., one where the speaker assesses the state of affairs described by its ' $\mathrm{X}$ is doing $Y^{\prime}$ part as undesirable or somehow wrong. We now turn our attention to the origin of this meaning implication and to the reason why the $\mathrm{Y}$ variable is important to convey it. Obviously, a sentence like What's your sister doing? can be an information question, where the speaker demands an answer that provides him with the information that he desires to have:

(2)

A: What's your sister doing?

B: I think she went out for a walk, but she should be back any minute.

B's response in (2) makes sense only under the assumption that B believes-or pretends that he believesthat $\mathrm{A}$ is only asking form information. But there can be other possible reactions to A's question. Here are a few, for the sake of illustration:

\section{(2')}

a. She's doing nothing wrong, as far as I can see.

b. She's no angel, I know.

c. I'll tell her to stop, don't worry.

d. I'm so sorry she's messing with your iPhone again.

e. Why don't you ask her yourself?
Each of the responses in (2') addresses the interrogative What's your sister doing? as a case of the What's $X$ Doing Y? construction. For this to be possible, the following assumptions are necessary:

a. The speaker is aware of what the actor is doing.

b. The speaker believes that the actor is doing something wrong.

c. The speaker believes that the hearer either shares assumption (b) or should share assumption (b) with him.

$\mathrm{d}$. The hearer believes assumptions (a)-(c) to be the case.

If these assumptions hold, then the hearer will take the sentence What's your sister doing? as an indication that the speaker dislikes what the hearer's sister is doing and will react accordingly, following cultural conventions. But what is the origin of these assumptions? The answer probably lies in the nonimplicational content of the interrogative sentence What's your sister doing?, which descriptively conveys the idea that the speaker knows that the hearer's sisters is actually doing something at the moment of speaking. The question is that it is unusual for someone to know that another person is doing something without being able to determine what it is. It may happen in contexts in which there are perceptual difficulties involved or in contexts where the speaker can perceive what other people are doing but has no way to determine their ultimate intentions. For example, imagine the speaker can see that the hearer's sister has the speaker's iPhone with her. He may still wonder why she has it and ask What's your sister doing? In this situation, a response in the form of She has your iPhone with her would be highly unsatisfactory, while an answer along the lines of (2'd) above would make sense.

Now, consider what happens, from the perspective of the assumptions that speaker and hearer share, when the speaker fleshes out the Y variable of the What's X Doing $Y$ ? construction, as in What's your sister doing with my iPhone?, or in What's your sister doing messing with my iPhone? The greater the degree of specificity of the Y variable, the stronger assumption (a) above becomes. The fact that the speaker is able to supply a greater degree of detail about the action is a clear indicator that the speaker can pin down its exact nature and is not really asking about it. This leads the hearer along an inferential pathway to find out the real speaker's intent. One plausible solution is that the speaker is not asking a question to derive information, but directing the hearer to ask himself the very same question that the speaker has asked him and thus become aware-like the speakerof what the actor is doing (This is an instance of what may be labeled non-contrastive echoing. An echo is an exact repetition of someone's real or attributed words. It happens in reported speech and also, combined with linguistic and paralinguistic signals of speaker's 
reservation, in irony. Ruiz de Mendoza (2014b) has postulated that irony results from formulating echoed thoughts that clash with what the speaker believes to be the case at the moment of speaking. Ironic uses of language are thus a matter of contrastive echoing. For a full exploration of the notion of echoing across levels of linguistic description, see Ruiz de Mendoza and Galera (2014)). Once the hearer shares with the speaker a sufficiently relevant set of assumptions about what the actor is doing, the hearer is expected to evaluate the state of affairs in question in the same way as the speaker, i.e., the hearer is expected to produce assumption (b) above and regard it as shared with the speaker, which is assumption (c). This last stage completes the inferential process that leads the hearer to interpret a What's $X$ Doing $Y$ ? configuration not as an information question but as a way of drawing the hearer's attention to a state of affairs that the speaker considers undesirable. Then, the presence of a well-specified Y component becomes a formal pointer to the likelihood of a linguistic expression being a case of the What's $X$ Doing $Y$ ? construction and, in the absence of an explicit Y component, as in (1a), the hearer's ability to match sentence form with contextual information will help the hearer disambiguate between the two options. This level of specialization of the formmeaning relationship, which arises from what Langacker (2000) has called "entrenchment", or frequency of association, is a natural result of the fact that it is difficult to make a fully descriptive use a What's $X$ Doing $Y$ ? utterance since it is odd to ask for information that the speaker already has. An interpretive use, grounded in inferential activity, is a meaningful solution to such an oddity.

\section{Who 's Been V-ing $X$ ?}

Like What's $X$ Doing $Y$ ?, the configuration Who's Been $V$-ing $X$ ? is also suggestive of speaker's discontent with a state of affairs. The following examples illustrate this characteristic of the Who's Been $V$-ing X? construction:

(3)

a. Who's been sleeping in my house?

b. Who's been swimming naked?

c. Who's been saying otherwise?

d. Who's been looking at my Facebook?

e. Who's been doing what?

However, there are formal and functional differences between the two constructions. First, unlike What's $X$ Doing $Y$ ?, the progressive form in Who's Been $V$-ing $X$ ? does carry progressive meaning (cf. *Who's been knowing the answer all the time?, but Who's been trying to find the answer?). Without this progressive form, the default value of the resulting construction is that of an information question, as is evident from the following examples:
(4)

a. Who's been here?

b. Who's been arrested?

c. Who's been naughty?

d. Who's been in love for so long?

e. Who's been this year's best player?

Second, in Who's Been $V$-ing $X$ ? there is no room for a fixed generic element (cf. doing in What's $X$ Doing $Y$ ?) requiring subsequent specification. There is a compelling reason for this. Wh-interrogatives asking about the subject carry the presupposition that the content of the predication holds true. For example, the question Who murdered Smith? presupposes that Smith has been murdered. The same holds for questions taking the Who's Been $V$-ing $X$ ? form, as exemplified in (3): (3a) presupposes that someone has been sleeping in the speaker's house, (3b) that someone has been swimming naked, (3c) that someone has been expressing (and still sustains) a different opinion, (3d) that someone has been looking at the speaker's Facebook, (3d) that, like any other year, this year someone must qualify as the best player and $(3 \mathrm{e})$ that someone has been doing something. Note, as is clear from (3e), that while a generic element like doing can be used in a Who's Been V-ing X? question, this element is never fixed, but one of the many possible instantiations of the $V$-ing part of the construction. From the speaker's perspective, the presupposed content of all these examples supplies the hearer with sufficient information to determine the identity of the subject, which is what he is asking about. There is no need to make any further specification, unless the hearer gives evidence to the contrary:

(5)

A: Who's been sleeping in my house?

B: You mean in your own bedroom?

There are other smaller differences with What's $X$ Doing Y? Thus, Who's Been V-ing X? can take the modifier else (Who else has been sleeping in my house?) and it can take the negative form (Who hasn't been working in today's class?). The use of else requires a brief reflection. Kay and Fillmore (1999) note that this modifier cannot be used with What's X Doing Y? But this holds true only for examples where the $Y$ variable contains a verb in gerund explicitly specifying the nature of the action, as in *What else are you doing eating cold pizza?, which the authors give. This does not apply to examples where the $\mathrm{Y}$ variable requires inferring the nature of the action generically invoked by doing: What (else) is he doing with my money every month? The version with else suggests that the speaker suspects that the actor could be doing something wrong besides what is already evident to him and to the hearer. 
Who's Been $V$-ing $X$ ? is part of a family of constructions, all based on the wh-interrogative form, which share with it a number of relevant characteristics, both in form and meaning:

What's $X$ Been V-ing Y?: What's he been doing with my money?

Where's $X$ Been ( $V$-ing) Y?: Where's he been (hanging out) all this time?

Why's X Been $V$-ing $Y$ ?: $\quad$ Why's he been flirting with this girl?

When's $X$ Been $V$-ing $Y$ ?: When's she been living in Liverpool?

Like Who's Been $V$-ing $X$ ?, these constructions presuppose the actuality, from the speaker's perspective, of the state of affairs that they describe. They can take the modifier else with the same meaning implications (e.g., What else has he been doing with my money? suggests that the speaker believes that the actor could have been misusing the speaker's money in more ways than those for which he has evidence) and they can appear in the negative form while preserving the meaning implication that there is something about the state of affairs that the speaker is only apparently asking about. In fact, this meaning implication is strengthened considerably, precisely because of the special nature of negation when applied in the context of an open-ended information question. For example, the sentence What hasn't he been doing with my money? implies that the actor has been almost invariable misusing the speaker's money. The same holds true of the rest of $w h$-questions above, although the one based on why requires special consideration. The negative form Why hasn't he been flirting with this girl?, as is to be expected with this construction, presupposes that the actor has not been flirting with a specific girl. But it does much more than simply convey this idea. This question seems to imply that the actor has been flirting with as many girls as possible but, for some reason, has chosen (or has been unable) to flirt with a specific girl, a situation that the speaker does not like or considers to be odd. In What hasn't he been doing with my money? there is no parallel implication that the actor has made an exception, but, all to the contrary, the implication is that the actor has done his best not to make any exception. The reason for this is to be found in focal prominence constraints. While in the what question above the only focal constituent is the wh pronoun itself, in the why question focal prominence is distributed between the $w h$ pronoun and the satellite with this girl (as opposed to other girls). In What's he been doing with my money? the phrase with my money is given information. What the negative form of $W h-X$ Been $V$-ing $Y$ ? constructions code is the following: (i) There is a state of affairs such that it holds true for any conceivable scenario.

(ii) The speaker dislikes (i).

(iii) Because of (ii) the speaker wishes he could find at least an exception to (i).

In the case of the sentence What hasn't he been doing with my money?, the implication-which arises from focal prominence on what-is that there will likely not be any exception, which the speaker believes is a rather undesirable situation. By contrast, Why hasn't he been flirting with this girl? conveys the meaning-arising from focalizing with this girl-that an exception has already been made, which is also undesirable.

\section{Illocutionary Constructions}

Illocutionary meaning is treated within Cognitive Linguistics as the result of the activation of illocutionary scenarios. This idea originated in preliminary work by Thornburg and Panther (1997) and Panther and Thornburg (1998). There have been subsequent elaborations by Pérez and Ruiz de Mendoza (2002; 2011), Panther (2005), Ruiz de Mendoza and Baicchi (2007), Baicchi and Ruiz de Mendoza (2010), Del Campo (2011; 2013), Pérez (2013) and Ruiz de Mendoza and Galera (2014). What these elaborations have in common is the postulation that illocutionary meaning derivation is based on the activation of selected conceptual structure stored in the form of cognitive models in the speakers' minds. However, they differ in the role allotted to inferential mechanisms and their true nature.

According to Panther and Thornburg (1998), for each illocutionary category in a language there is an associated knowledge structure containing information organized in terms of degrees of centrality, as is the case with other knowledge structures (Langacker, 1987; 2008). For requests, Panther and Thornburg (1998) propose the following illocutionary scenario, whose different components are inspired in the well-known felicity conditions for speech acts postulated by Searle (1969):

a. Before component: He hearer $(\mathrm{H})$ can do the action (A). The speaker (S) wants $\mathrm{H}$ to do A.

b. Core component: $\mathrm{S}$ puts $\mathrm{H}$ under the (more or less strong) obligation to do $\mathrm{A}$. $\mathrm{H}$ is under an obligation to do A (H must/should/ought to do A).

c. After component: $\mathrm{H}$ will do $\mathrm{A}$. $\mathrm{S}$ has an emotional response.

Any linguistic expression that activates one of the elements within one of these three components can be interpreted as a request if it can metonymically stand for the rest of the scenario. This is why, for example, 
a question about the hearer's ability or willingness to perform an action (which are part of the "before" component), by affording access to the whole request scenario, acquires a request value: Can/will you tell me the truth? ('Tell me the truth'). The core component can be invoked by means of a sentence expressing any degree of obligation to perform an action (You must/should tell me the truth) and the after component by expressions denoting its prospective performance (You will tell me the truth, won't you?).

There are two basic limitations in Panther and Thornburg's initial proposal. One is that the account of speech act meaning in terms of before, core and after components is not delicate enough to distinguish degrees of imposition and, consequently, of politeness. As Pérez and Ruiz de Mendoza (2002; 2011) and Pérez (2013) have noted, illocutionary scenarios need to be enriched with other elements (e.g., the speaker's will, the addressee's willingness, social distance, power, etc.) before real illocutionary intent can be accounted for. Thus, the difference in meaning between Can/could you tell me the truth? is a question of mitigating the impact of the speech act through indirectness (cf. the classic accounts in Leech (1983) and Brown and Levinson (1987)). To date, Pérez (2013) is the most detailed study on the relationships among the various socio-cultural components of an illocutionary scenario or cognitive model, following the now standard terminology found in Lakoff (1987). A second limitation in Panther and Thornburg's preliminary account has to do with its inability to deal with inferred illocution adequately. For example, the sentence I need to know the truth can easily count as a request for the hearer to tell the truth to the speaker. But, while it could be argued that its illocutionary value hinges one of the elements of the "before" component, i.e., that the speaker wants the hearer to perform the action, what the speaker actually does is express a need rather than a want. For adequate interpretation, the hearer is required to reason that if the speaker needs something, he probably wants it too. Or think of a stock example of indirect illocution such as I'm starving. Here, there is a more complex inferential jump. There is (i) a negative state of affairs that creates a problem that (ii) needs to be solved, which links up with (iii) the likelihood that the speaker wants it solved by the hearer. The stipulations in the high-level situational model called the Cost-Benefit Cognitive Model, one of which was briefly discussed above, could provide a satisfactory solution to this shortcoming in the illocutionary scenarios account. The one discussed in a previous section applies in the present case. Roughly speaking, the stipulation captures the socio-cultural convention that we need to do our best to help other people when we become aware that they are involved in a non-beneficial state of affairs. This can be made manifest directly (e.g., I'm starving), or indirectly by manifesting a desire (e.g., I want to know the truth) or a need (e.g., I need to know the truth), both of which imply that the speaker is not fully satisfied about a certain state of affairs. The same stipulation is exploited when asked about our capacity or willingness to modify a state of affairs to the speaker's benefit (Can/will you tell me the truth?).

The Cost-Benefit Cognitive model allows us to cut across illocutionary categories and at the same time to explore a more complex range of meaning implications than illocutionary scenarios. For example, the stipulation cited above underlies these other expressions:

(6)

a. Why didn't you tell me the truth?

b. You should have told me the truth; I needed to know.

c. But couldn't you just tell me the truth?

d. You could have told me the truth, couldn't you?

e. Don't you think you could have told me the truth?

Let us briefly consider each of the examples in (6). In (6a) the speaker feels he has a right to complain about the hearer not telling him the truth. The strategy is to ask the hearer for the reason why he did not tell the truth, i.e., the reason why he did not follow the social convention. There are some possible options. For example, the hearer could have been unaware that he was expected to disclose some information. This is a different, not necessarily directive, exploitation of the well-known ability condition in Searle (1969; 1975 ) for the category of requests and it is part of the "before" component in Panther and Thornburg's (1998) analysis. Another possibility is that the speaker had reasons to be reluctant to sharing the information. Again, this is another Searle an condition for requests, the willingness condition, which has also been incorporated into Panther and Thornburg's "before" component. A third possibility is that the speaker did not have the required information. This is a different exploitation of the ability condition. A fourth possibility is that the hearer believed that telling the truth to his interlocutor could do him harm. This is another way of activating the willingness condition, i.e., the hearer does not want to do harm to the speaker. Example (6b) is also a complaint, but it is based on a different strategy. Here the speaker expresses his opinion (the literal value coded by you should) that the hearer should have told him the truth. This is complemented by a justification (I needed to know), which is, in any case, optional. The justification works by making the speaker's need explicit. If left unexpressed, the existence of such a need can be inferred from the expression of the speaker's opinion that an action should have been performed to the speaker's interest (telling someone the truth could be harmful, but any potential harm is overridden by the speaker stating his right to know the truth). In this example, the ability and willingness conditions only play a secondary role, if any. The 
focus of attention is on the speaker being entitled to be told the truth on the grounds of the speaker's own interest. Example (6c), by contrast, hinges on the ability condition in a direct way. The interrogative negative form conveys speaker's frustration or even irritation by the hearer not acting they way he is expected to. This meaning implication is reinforced by the use of the adverb just, which signals the inherent simplicity of acting according to established sociocultural convention rather than counter to it. The rationale behind this meaning implication can be understood if contrasted with an affirmative interrogative could you version of the same sentence: Could you (just) tell me the truth? Literally, the affirmative question asks about the hearer's ability to do as is expected of him. Logically, if the hearer has no such ability, the request makes no sense. The negative question, by contrast, presupposes that the hearer has not done anything yet. This prompts the speaker to wonder whether the hearer may not be capable of doing the required action. Since, contrary to the speaker's desire, the action has not been carried out, the negative question about the hearer's ability is generally associated with the speaker's frustration, which is implicational rather than illocutionary meaning. Example (6d) is very similar to (6c) in this respect. The difference is one of focal prominence. While (6c) focalizes the action that has not been performed, (6d) gives focal prominence to the tag that codes the speaker's frustration following the same implicational process that we have just described for (6c). Finally, (6e) bases its directive meaning on questioning the hearer about him being aware of his inaction in a situation in which he probably had the ability to act.

The expressions in (6) are all examples of illocutionary constructions since they represent stable form-meaning associations. Compare:

(7)

a. Why didn't you tell me there was danger?

b. Why didn't you say so?

c. Why didn't you do your homework?

\section{(8)}

a. You should have taken some driving lessons beforehand.

b. You should have refused his offer.

c. You should have stopped when I asked.

(9)

a. But couldn't you (just) leave him?

b. But couldn't you (just) ask?

c. But couldn't you (just) keep out of their way?

(10)

a. You could have phoned me to let me known, couldn't you?

b. You could have saved the data, couldn't you?

c. You could have tried harder, couldn't you?
(11)

a. Don't you think you could have thought of something more practical?

b. Don't you think you could have been more tactful?

c. Don't you think you could have asked what I wanted?

Of course, as with other implicational and illocutionary constructions, the same form can sometimes give access to other meanings. For example, You could have been a great musician can be easily interpreted as a lament about the hearer's thwarted attempts to excel in the field of music. But, along the lines of the examples in (10), the same sentence could also be a complaint or a way to move the hearer to take action for his own benefit and resume his musical career.

Illocutionary constructions also form constructional families whose various members supply different shades of illocutionary meaning. For example, there are constructions that code a very basic directive meaning, such as Can You X (Please)?, or Will You X (Please)? But it is possible to endow the linguistic expression with greater degrees of formality through indirectness: Could You X (Please)?, Would You X (Please)?, Do You Think You Could X (Please)?, Would You Mind X?, I Would Appreciate If You X, I Wonder If You Could X. Since these latter constructions are developments of the basic ones, we can think of them in terms of parent-daughter relationships. Daughter constructions, which are sisters to one another, inherit basic meaning from parent constructions. Pérez (2013) has accounted for this relationship in a very interesting way. She argues that what we here call daughter constructions are specifications of base constructions (our basic types above). The specification process is regulated by the internal conventions included in the cognitive model for a given speech act category. For example, in the case of requests, the larger the amount of social distance, which is part of the corresponding cognitive model, the greater the need will be to include mitigation devices in the more specific construction. In this process, a base request construction, as illustrated by the sentence $C a n$ you remove the image?, will be hedged on the basis of an optionality specification link (e.g., If you don't mind), a mitigation specification link (e.g., one converting can into could) and a cost-benefit specification link (e.g., $j u s t$ ) resulting in the final constructional output, which is illustrated by the sentence: If you don't mind, could you just remove the image? It goes without saying that the components of this constructional specification need to be conceptually and formally compatible. Constructional behavior is a matter of associating form and meaning in ways that are recognizably meaningful for the hearer. In this process, speakers may either use constructional variants (whether parents or daughters) that are accessible to them from their own knowledge store or 
they may create their own. Speakers may or may not be aware that they have created a construction. In any event, a new construction can catch on among a community of speakers or simply turn out to be a one-off occurrence.

\section{Conclusion}

The present article has offered an in-depth discussion of the notion of construction. It has gone beyond previous discussion within Cognitive Linguistics in two ways. First, it has provided different criteria to classify constructions (in terms of combinability, fixity and meaning representation). Second, it has addressed the question of how constructional meaning that does not arise from the argument-structure properties of predications is formed. It has thus focused its attention on implicational and illocutionary constructions. Both are based, from the point of view of meaning representation, on situational cognitive models or scenarios, the difference between the two types being a matter of the greater degree of genericity of the semantic base of illocutionary type. Because of this similarity, the meaning implications of constructions of the two kinds are obtained on the basis of comparable meaning-derivation mechanisms, i.e., inferences based on the activation of relevant structure from (low-or high-level) scenarios. We have illustrated how implicational and illocutionary constructions capture entrenched meaning implications by means of three case studies: The implicational What's $X$ Doing $Y$ ? construction, the family of $W h$-'s $(X)$ Been ( $V$-ing) $(Y)$ ? constructions and a sample of illocutionary constructions exploiting one of the stipulations of Ruiz de Mendoza and Baicchi's (2007) Cost-Benefit Cognitive Model. Each of the stipulations in this model is a high-level scenario regulating socio-cultural expectations on how people interact. The correlation between socio-cultural conventions, meaning inferences and formal patterns has revealed the existence of commonalities and differences among constructions thereby allowing us to capture relevant relations among constructional variants. Further research, of a quantitative kind, is now required in order to further systematize (and empirically validate) the proposals in the present paper.

\section{Acknowledgement}

The author is grateful to the editor of the present special issue of this journal, Dr. María Isabel González Rey, for her kind invitation to contribute and to the anonymous referees of this paper for their constructive comments on a previous version. Any remaining problem is the author's own responsibility. This paper is dedicated to professor Günter Radden (Hamburg University) on the occasion of his 80th birthday on July 11,2014 , for a lifetime of fertile and influential devotion to the study of language.

\section{Funding Information}

The present research has been financed by the Spanish Ministry of Economy and Competitiveness, grant no. FFI2013-43593-P.

\section{Ethics}

The author hereby declares that there is not any ethical issue or conflict of interest arising from the present article or the research on which its is based.

\section{References}

Baicchi, A. and F. Ruiz de Mendoza, 2010. The cognitive grounding of illocutionary constructions within the theoretical perspective of the lexicalconstructional model. Textus. Eng. Studies Italy, 23: 543-563. DOI: 10.1400/170187

Barðdal, J., V. Bjarnadóttir, G.B. Jenset and T. Smitherman, 2014. Reconstructing constructional semantics: The dative subject construction in Old Norse-Icelandic, Latin, Ancient Greek, Old Russian and Old Lithuanian. In: Theory and Data in Cognitive Linguistics, Gisborne, N. and W. Hollmann (Eds.), John Benjamins Publishing Company, Amsterdam, ISBN-10: 9027242550, pp: 49-85.

Boas, H.C., 2003. A Constructional Approach to Resultatives. 2nd Edn., CSLI Publications, Stanford, ISBN-10: 1575864088, pp: 400.

Brown, P. and S. C. Levinson, 1987. Politeness: Some Universals in Language Usage. 1st Edn., Cambridge University Press, Cambridge, ISBN-10: 0521313554, pp: 358.

Colleman, T. and B. De Clerck, 2008. Accounting for ditransitive constructions with envy and forgive. Functions Lang. 15: 187-215. DOI: $10.1075 /$ fol.15.2.02col

Del Campo, N., 2011. Cognitive modeling in illocutionary meaning. Rev. Cognitive Linguist., 9: 392-412. DOI: 10.1075/rcl.9.2.03del

Del Campo, N., 2013. Illocutionary Constructions in English: Cognitive Motivation and Linguistic Realization: A Study of the Syntactic Realizations of the Directive, Commissive and Expressive Speech Acts in English. 1st Edn., Peter Lang Pub Incorporated, Bern, ISBN-10: 3034312997, pp: 324.

Dirven, R. and F. Ruiz de Mendoza, 2010. Looking Back at 30 Years of Cognitive Linguistics. In: Cognitive Linguistics in Action: From Theory to Application and Back, Tabakowska, E., M. Choiński and $Ł$. Wiraszka (Eds.), Walter de Gruyter, Berlin, ISBN10: 311022609X, pp: 13-70.

Goldberg, A.E. and R. Jackendoff, 2004. The English resultative as a family of constructions. Language, 80: 532-568. DOI: 10.1353/lan.2004.0129 
Goldberg, A.E., 1995. Constructions: A Construction Grammar Approach to Argument Structure. 1st Edn., University of Chicago Press, Chicago, ISBN: 0226300862, pp: 265.

Goldberg, A.E., 1998. Patterns of Experience in Patterns of Language. In: The New Psychology of Language, Tomasello, M. (Ed.), Lawrence Erlbaum, Mahwah, N.J., ISBN-10: 9780805834284, pp: 203-219.

Goldberg, A.E., 2003. Constructions: A new theoretical approach to language. Trends Cognitive Sci., 7: 219-224. DOI: 10.1016/S1364-6613(03)00080-9

Goldberg, A.E., 2006. Constructions at Work: The Nature of Generalization in Language. 1st Edn., Oxford University Press, Oxford, ISBN-10: 0199268517, pp: 280.

Hampe, B., 2005. From Perception to Meaning: Image Schemas in Cognitive Linguistics. 1st Edn., Walter de Gruyter, Berlin New York Mouton de Gruyter, ISBN-10: 3110183110, pp: 485.

Hundt, M., 2007. English Mediopassive Constructions: A Cognitive, Corpus-based Study of Their Origin, Spread and Current Status. 1st Edn., Rodopi, Amsterdam, ISBN-10: 9042021276, pp: 222.

Johnson, M., 1987. The Body in the Mind: The Bodily Basis of Meaning, Imagination and Reason. 1st Edn., University of Chicago Press, Chicago, ISBN-10: 0226403181, pp: 272.

Kay, P. and C. Fillmore, 1999. Grammatical constructions and linguistic generalizations: The what's $\mathrm{X}$ doing $\mathrm{Y}$ ? construction. Language, 75: 1-33.

DOI: $10.2307 / 417472$

Lakoff, G., 1989. Some empirical results about the nature of concepts. Mind Language, 4: 103-129. DOI: 10.1111/j.1468-0017.1989.tb00244.x

Lakoff, G., 1987. Women, Fire and Dangerous Things: What Categories Reveal about the Mind. 1st Edn., University of Chicago, Chicago, ISBN-13: 9780226468044, pp: 614.

Lakoff, G., 1993. The Contemporary Theory of Metaphor. In: Metaphor and Thought. Ortony, A. (Ed.), Cambridge University Press, Cambridge, ISBN-10: 0521405610, pp: 202-251.

Langacker, R., 1987. Foundations of Cognitive Grammar: Theoretical Prerequisites. 1st Edn., Stanford University Press, Stanford, ISBN-10: 0804738513, pp: 540.

Langacker, R., 2000. Grammar and Conceptualization. 1st Edn., Walter de Gruyter, Berlin, ISBN-10: 3110166046, pp: 427.

Langacker, R., 2008. Cognitive Grammar: A Basic Introduction. 1st Edn., Oxford University Press, USA, New York, ISBN-10: 0195331958, pp: 584.

Leech, G.N., 1983. Principles of Pragmatics. 1st Edn., Longman, London, ISBN-13: 9780582551107 , pp: 264.
Levin, B., 1993. English Verb Classes and Alternations: A Preliminary Investigation. 1st Edn., University of Chicago Press, Chicago, ISBN-10: 0226475336, pp: 348.

Mairal, R. And F. Ruiz de Mendoza, 2009. Levels of description and explanation in meaning construction. In: Deconstructing constructions, Butler, C. and J. Martín Arista (Eds.), John Benjamins Publishing, Amsterdam, ISBN-10: 9027205744, pp. 153-198.

Michaelis, L., 2003. Word Meaning, Sentence Meaning and Syntactic Meaning. In: Cognitive Approaches to Lexical Semantics, Cuyckens, H., R. Dirven and J.R. Taylor (Eds.), Walter de Gruyter, Berlin, ISBN10: 3110177099, pp: 93-122.

Michaelis, L., 2004. Type shifting in Construction Grammar: An integrated approach to aspectual coercion. Cognitive Linguist., 15: 1-67. DOI: $10.1515 / \operatorname{cog} 1.2004 .001$

Nolan, B., 2013. Constructions as Grammatical Objects: A Case Study of the Propositional Ditransitive Construction in Modern Irish. In: Linking Constructions into Functional Linguistics: The Role of Constructions in Grammar, Nolan, B. and E. Diedrichsen (Eds.), John Benjamins Publishing Company, Amsterdam, ISBN-10: 9027271089 pp: 143-178.

Panther, K., 2005. The Role of Conceptual Metonymy in Meaning Construction. In: Cognitive Linguistics: Internal Dynamics and Interdisciplinary Interaction, Ruiz de Mendoza, F. and S. Peña (Eds.), Walter de Gruyter, Berlin, ISBN-10: 3110186179, pp: 353-386.

Panther, K. and L. Thornburg, 1998. A cognitive approach to inferencing in conversation. J. Pragmat., 30: 755-769. DOI: 10.1016/S0378-2166(98)00028-9

Peña, S., 2003. Topology and Cognition: What Imageschemas Reveal about the Metaphorical Language of Emotions. 1st Edn., Lincom GmbH, München, Muenchen LINCOM Europa, ISBN-10: 3895863092, pp: 311 .

Peña, S., 2008. Dependency systems for imageschematic patterns in a usage-based approach to language. J. Pragmat., 40: 1041-1066.

DOI: $10.1016 /$ j.pragma.2008.03.001

Peña, S. and F. Ruiz de Mendoza, 2009. Metonymic and Metaphoric Bases of Two Image-Schema Transformations. In: Metonymy and Metaphor in Grammar, Panther, K., L. Thornburg and A. Barcelona (Eds.), John Benjamins Publishing, Amsterdam, ISBN-10: 9027223793, pp: 339-361.

Pérez, L. 2013. Illocutionary constructions: (Multiple source)-in-target metonymies, illocutionary ICMs and specification links. Lang. Commun., 33: 128-149. DOI: 10.1016/j.langcom.2013.02.001 
Pérez, L. and F. Ruiz de Mendoza, 2002. Grounding, semantic motivation and conceptual interaction in indirect directive speech acts. J. Pragmat., 34: 259-284. DOI: 10.1016/S0378-2166(02)80002-9

Pérez, L. and F. Ruiz de Mendoza, 2011. A lexical constructional model account of illocution. Vigo Int. J. Applied Linguist., 8: 99-138.

Pustejovsky, J., 1993. Type Coercion and Lexical Selection. In: Semantics and the Lexicon, Pustejovsky, J. (Ed.), Springer, Dordrecht, ISBN-10: 079231963X, pp: 73-96.

Radden, G. and R. Dirven, 2007. Cognitive English Grammar. 1st Edn., John Benjamins Publishing, Amsterdam, ISBN-10: 1556196636, pp: 374.

Ruiz de Mendoza, F., 2001. Lingüística Cognitiva: Semántica, Pragmática y Construcciones. Universidad de La Rioja. Círculo de Lingüística Aplicada a la Comunicación 8: 1-32.

Ruiz de Mendoza, F. and A. Baicchi, 2007. Illocutionary Constructions in English: Cognitive Motivation and Linguistic Realization. In: Explorations in Pragmatics: Linguistic, Cognitive and Intercultural Aspects, Kecskes, I. and L. Horn (Eds.), Walter de Gruyter, Berlin, ISBN-10: 3110193663, pp: 95-128.

Ruiz de Mendoza, F. and R. Mairal, 2008. Levels of description and constraining factors in meaning construction: An introduction to the Lexical Constructional Model. Folia Linguistica Acta Societatis Linguisticae Europaea, 42: 355-400. DOI: $10.1515 /$ FLIN.2008.355

Ruiz de Mendoza, F. and S. Peña, 2008. Gramatical metonymy within the "action" frame in English and Spanish. In: Current Trends in Contrastive Linguistics: Functional and Cognitive Perspectives, Gómez, M., L. Mackenzie and E.M. González (Eds.), John Benjamins, Amsterdam, ISBN-10: 9027215715, pp: 251-280.

Ruiz de Mendoza, F. and R. Mairal, 2011. Constraints on syntactic alternation: Lexical-constructional subsumption in the Lexical Constructional Model. In: Morphosyntactic Alternations in English: Functional and Cognitive Perspectives, Medina, P.G., (Ed.), Equinox Pub. Limited, London, ISBN-10: 1845537440, pp: 62-82.

Ruiz de Mendoza, F. and A. Galera. 2014. Cognitive Modeling. A Linguistic Perspective. John Benjamins Publishing, Amsterdam, ISBN 9789027223999, pp: 250.

Ruiz de Mendoza, F., 1999. La Ilocución Y La Gramática. In: Nuevas Perspectivas en Gramática Funcional, Butler, C., R. Mairal, J. Martín and F.R. de Mendoza (Eds.), Ariel, Barcelona, ISBN-10: 9788434482319, pp: 99-171.
Ruiz de Mendoza, F., 2013. Meaning Construction, Meaning Interpretation and Formal Expression in the Lexical Constructional Model. In: Linking Constructions into Functional Linguistics: The Role of Constructions in Grammar, Nolan, B. and E. Diedrichsen (Eds.), John Benjamins Publishing Company, Amsterdam, ISBN-10: 9027271089, pp: 231-270.

Ruiz de Mendoza, F., 2014a. Low-level situational cognitive models within the Lexical Constructional Model and their computational implementation in FunGramKB. In: Language Processing and Grammars: The Role of Functionally Oriented Computational Models, Nolan, B. and C. Periñán-Pascual (Eds.), John Benjamins Publishing Company, Amsterdam, ISBN-10: 9027270643, pp: 367-390.

Ruiz de Mendoza, F., 2014b. Mapping concepts: Understanding figurative thought from a cognitivelinguistic perspective. Spanish J. Applied Linguist., 27: 187-207. DOI: 10.1075/resla.27.1.08rui

Schank, R.C. and R.P. Abelson, 1977. Scripts, Plans, Goals and Understanding. 1st Edn., Lawrence Erlbaum Associates, Hillsdale, ISBN-10: 0470990333, pp: 268.

Searle, J.R., 1969. Speech Acts: An Essay in the Philosophy of Language. 1st Edn., Cambridge University Press, Cambridge, ISBN-10: 052109626X, pp: 203.

Searle, J.R., 1975. A Taxonomy of Illocutionary Acts. In: Language, Mind and Knowledge, Gunderson, K. (Ed.), University of Minnesota Press, Minneapolis, ISBN-10: 0816657793. pp: 344-369.

Stefanowitsch, A., 2003. A Construction-Based Approach to Indirect Speech Acts. In: Metonymy and Pragmatic Inferencing, Panther, K.U. and L. Thornburg (Eds.), John Benjamins Publishing, Amsterdam, ISBN-10: 9027253552, pp: 105-26.

Talmy, L., 2000a. Toward a Cognitive Semantics. Vol. I: Concept Structuring Systems. 1st Edn., MIT Press, Cambridge, ISBN-10: 0262201208, pp: 573.

Talmy, L., 2000b. Toward a Cognitive Semantics, Vol. II: Typology and Process in Concept Structuring. 1st Edn., MIT Press, Cambridge, ISBN-10: 0262201216, pp: 503.

Thornburg, L. and K. Panther, 1997. Speech Act Metonymies. In: Discourse and Perspective in Cognitive Linguistics, Liebert, W.A., G. Redeker and L.R. Waugh (Eds.), John Benjamins Publishing, Amsterdam, ISBN-10: 9027236550, pp: 205-219.

Wilson, D., 2006. The pragmatics of verbal irony: Echo or pretence? Lingua, 116: 1722-1743. DOI: 10.1016/j.lingua.2006.05.001

Wilson, D. and D. Sperber, 2012. Explaining Irony. In: Meaning and Relevance, Wilson, D. and D. Sperber (Eds.), Cambridge University Press, Cambridge, ISBN-10: 052176677X, pp: 123-145. 